Journal of Computer Science 6 (8): 886-895, 2010

ISSN 1549-3636

(C) 2010 Science Publications

\title{
Control of a Step Walking Combined to Arms Swinging for a Three Dimensional Humanoid Prototype
}

\author{
Amira Aloulou and Olfa Boubaker \\ Department of Physical Engineering and Instrumentation, \\ National Institute of Applied Sciences and Technology, University of Carthage, \\ INSAT, Centre Urbain Nord, BP 676-1080 Tunis Cedex, Tunisia
}

\begin{abstract}
Problem statement: Present researches focus to make humanoid robots more and more autonomous so they can assist human in daily works like taking care of children, aged or disabled persons. In such social activities, the contemporary humanoid robots are expected to have human like morphology and gait. Studies on bipedal locomotion for humanoid robots are then part of the hottest topics in the field of robotic researches. Knowing the benefits of arm swinging for human gait, we propose in this study a new prototype of female humanoid robot morphology having the capabilities to swing arms during step walking. Approach: A new humanoid robot prototype had been introduced based on a human morphology corresponding to a woman whose weight is $70 \mathrm{~kg}$ and height is $1,73 \mathrm{~m}$ and using realistic gait parameters of a women. The female humanoid robot prototype was composed of fifteen links associated to twenty-six degrees of freedom. Winter statistical model had been applied to determine all physical parameters corresponding to each link. Modeling the proposed humanoid robot implies first to establish the kinematic model basically founded on Euler's transformation matrix and then to set the dynamic model computed using the Newton-Euler method. To show how the arms played an important role in bipedal gait, we had chosen to consider the whole body as two independent robotic systems: the upper body and the lower body. Results: Both three dimensional kinematic and dynamic models of the humanoid robot had been developed. The three dimensional humanoid robot was controlled via a feedback linearization control during the single support, impact and double support phases. The simulation results showed the arm swing during the step of walking. Conclusion: The humanoid robot proposed has a human like morphology and ensures the function of a step walking with arm swinging. The applied control laws have ensured to the robot desired performances during a step walking.
\end{abstract}

Key words: Human morphology, humanoid robot, three dimensional modeling, motion control

\section{INTRODUCTION}

Humanoid robots are the materialization of science-fiction wildest dreams. Nowadays, they are the concentration point of multiple questions that robotics aims to solve. Indeed, they constitute enormous stakes due to the complexity of their mechanic, electronic and computer structures but also due to results and consequences that such successful projects may imply.

Currently, several Human morphologies are to be found in anthropomorphic literature (Winter, 2009) and used to represent various humanoid models capable of realizing human-like tasks or having functionalities usually admitted as "Human specific abilities". In Table 1, a revealing representative but not exhaustive analogy of the main emblematic humanoid robots is established. Three humanoids issued from three different continents and thus three various cultures are at play: Asimo (Chesnutt et al., 2005) from Japan, Rabbit (Chemori and Alamir, 2006) from France and Cog (Brooks et al., 1999) from US. Generally speaking, it appears that Asians and more specifically Japanese and Koreans have attached great importance to the study of the whole body of humanoid robots that take a human appearance and adopt a human behavior. Asia is leading the world in biped locomotion and business development of humanoids. As a reference, Japan has the largest population of humanoid systems. On the other hand, Americans have mostly focused their attention on the humanoid upper body study trying to reproduce a sensorial behavior close to the Human's one. Moreover, the US leads in algorithm developments.

Corresponding Author: Olfa Boubaker, Department of Physical Engineering and Instrumentation,

National Institute of Applied Sciences and Technology, University of Carthage, INSAT,

Centre Urbain Nord, BP 676-1080 Tunis Cedex, Tunisia 
Table 1: Comparison between three emblematic Humanoids

\begin{tabular}{|c|c|c|c|}
\hline & ASIMO (Japan) & Rabbit (France) & $\operatorname{Cog}$ (US) \\
\hline Creation year & 2005 & 2001 & 1996 \\
\hline Laboratory & Honda $\mathrm{R}$ and $\mathrm{D}$ laboratory & $\begin{array}{l}\text { Grenoble automatic laboratory/ } \\
\text { ROBEA program }\end{array}$ & MIT artificial intelligence laboratory \\
\hline Weight & $54 \mathrm{~kg}$ & $32 \mathrm{~kg}$ & - \\
\hline Height & $1,3 \mathrm{~m}$ & $1,425 \mathrm{~m}$ & - \\
\hline Anatomy & Whole human body & Torso and legs & Head, torso, one arm and one hand \\
\hline Functions & $\begin{array}{l}\text { Walking, running, using stairs, } \\
\text { voice and face recognition and } \\
\text { communication }\end{array}$ & Walking and running & Seeing, hearing and grasping objects \\
\hline Total DOF & & 3 or 7 depending on the walking phase & 22 \\
\hline
\end{tabular}

Regarding Europeans, their researches are nearly exclusively concentrated on bipedal gait and its subsidiary activities which include climbing stairs and running. As far as we know, the humanoid robot proposed in this study is the first African humanoid prototype. It will be distinguished by two characteristics: first, the whole body has been separated into lower body and upper body to emphasize the arms swing effect on the biped gait. Second, the whole motion is planned in the three dimensional space without decomposition in sagittal and frontal planes. Knowing that Humans swing their arms as they walk, there must be a certain number of possible benefits to arm swinging (Pontzer et al., 2009; Bruijn et al., 2008). To realize this concept, we have chosen to consider the whole body of the humanoid robot as two independent robotic systems: the upper body and the lower body that should be synchronized in future study. Furthermore, when modeling and controlling bipedal and humanoid robots, most works to be found in literature decomposed the motion study in the sagittal and frontal planes (Chevallereau et al., 2009; Cho et al., 2009). As far as we know, very few works give such models due to the very complicated developments imposed by this kind of strategy. In this context, we are inspired by those developed by Hemami and Zheng (1984).

\section{MATERIALS AND METHODS}

The morphological constitution of the humanoid robot corresponds to a human being's whole anatomy with a weight of $70 \mathrm{~kg}$ and a height of $1,73 \mathrm{~m}$ (Aloulou and Boubaker, 2010). Figure 1 and Table 2 show the involved rotations for each link.

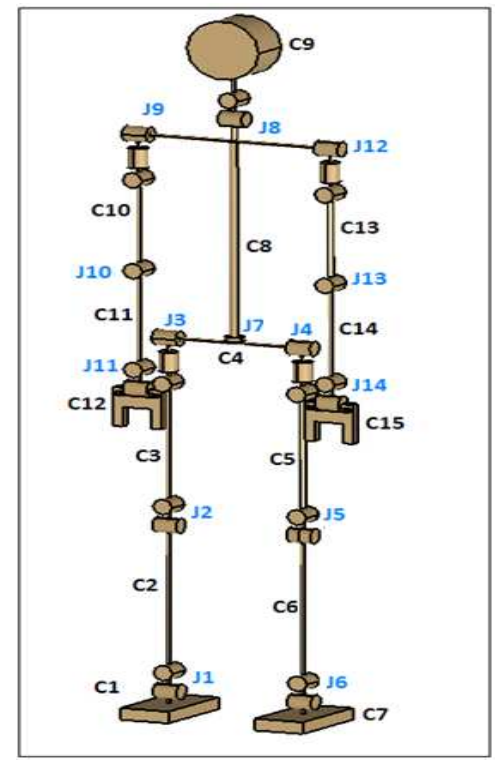

Fig. 1: Humanoid robot prototype

We have chosen to consider the whole humanoid robot as two independent robotic systems: the upper body and the lower body and then to present their modeling and analysis separately. The humanoid's separation aims to show the great role played by arms in better gait stabilization. As a consequence, two kinematic and dynamic models of the humanoid robot will be introduced and two different control laws will be adopted to ensure the main function of a walking step combined to arms swinging. Connection between upper and lower bodies is made by a passive joint. 
J. Computer Sci., 6 (8): 886-895, 2010

Table 2: Rigid bodies and articulations

\begin{tabular}{|c|c|c|c|c|}
\hline Link & $\begin{array}{l}\text { Link } \\
\text { description }\end{array}$ & Joint & $\begin{array}{l}\text { Joint } \\
\text { description }\end{array}$ & $\begin{array}{l}\text { Degrees of } \\
\text { freedom }\end{array}$ \\
\hline $\mathrm{C} 1$ & Right foot & $\mathrm{J} 1$ & Right ankle & 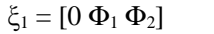 \\
\hline $\mathrm{C} 2$ & Right leg & $\mathrm{J} 2$ & Right knee & $\xi_{2}=\left[\begin{array}{lll}0 & \phi_{1} & \Phi_{3}\end{array}\right]$ \\
\hline $\mathrm{C} 3$ & Right thigh & $\mathrm{J} 3$ & Right hip & $\xi_{3}=\left[\Phi_{4} \Phi_{5} \Phi_{6}\right]$ \\
\hline $\mathrm{C} 4$ & Pelvis & $\mathrm{J} 7$ & Passive joint & $\xi_{4}=\left[\begin{array}{lll}0 & 0 & 0\end{array}\right]$ \\
\hline C5 & Left thigh & $\mathrm{J} 4$ & Left hip & $\xi_{5}=\left[\Phi_{7} \Phi_{8} \Phi_{9}\right]$ \\
\hline C6 & Left leg & $\mathrm{J} 5$ & Left knee & $\xi_{6}=\left[0 \Phi_{10} \Phi_{11}\right]$ \\
\hline $\mathrm{C} 7$ & Left foot & $\mathrm{J} 6$ & Left ankle & $\xi_{7}=\left[\begin{array}{lll}0 & \Phi_{10} & \Phi_{12}\end{array}\right]$ \\
\hline $\mathrm{C} 8$ & Trunk & $\mathrm{J} 7$ & Passive joint & $\xi_{8}=\left[\begin{array}{lll}0 & 0 & 0\end{array}\right]$ \\
\hline C9 & Head and neck & $\mathrm{J} 8$ & Neck & $\xi_{9}=\left[\begin{array}{lll}0 & \Phi_{13} & \Phi_{14}\end{array}\right]$ \\
\hline C10 & Right arm & J9 & Right shoulder & $\xi_{10}=\left[\Phi_{15} \Phi_{16} \Phi_{17}\right]$ \\
\hline C11 & Right forearm & $\mathrm{J} 10$ & Right elbow & $\xi_{11}=\left[\begin{array}{lll}0 & \Phi_{18} & 0\end{array}\right]$ \\
\hline $\mathrm{C} 12$ & Right hand & J11 & Right wrist & $\xi_{12}=\left[\begin{array}{lll}0 & \Phi_{19} & \phi_{20}\end{array}\right]$ \\
\hline $\mathrm{C} 13$ & Left arm & $\mathrm{J} 12$ & Left shoulder & 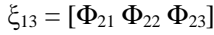 \\
\hline C14 & Left forearm & J13 & Left elbow & $\xi_{14}=\left[\begin{array}{lll}0 & \Phi_{24} & 0\end{array}\right]$ \\
\hline $\mathrm{C} 15$ & Left hand & J14 & Left wrist & $\xi_{15}=\left[\begin{array}{lll}0 & \Phi_{25} & \Phi_{26}\end{array}\right]$ \\
\hline
\end{tabular}

On the other hand, trunk and pelvis rigid bodies are assumed not to be subject to rotations however their mere presence allows the rigid bodies they are linked to moving in a correct way. As assumptions, we suppose that the torques at the ankle joints $\mathrm{J} 1$ and $\mathrm{J} 7$ between foots (rigid bodies $\mathrm{C} 1$ and $\mathrm{C} 7$ ) and the ground must be zero if foots are not in contact with the ground. From another side, the humanoid robot is assumed to always have a fixed contact point with the ground.

Anthropometric model: Physical parameters involved in the kinematic and dynamic models are computed. Each rigid body $\mathrm{C}_{\mathrm{i}}$ of the humanoid robot is characterized by the following physical parameters:

- $\mathrm{m}_{\mathrm{i}} \in \Re$ : Mass of the link $\mathrm{C}_{\mathrm{i}}$

- $\mathrm{i}_{\mathrm{i}} \in \Re$ : Inertia about the center of mass of the link $\mathrm{C}_{\mathrm{i}}$

- $\mathrm{k}_{\mathrm{i}} \in \Re$ : Proximal distance defined as the distance from the center of gravity to the connect joint of the previous link $\mathrm{C}_{\mathrm{i}-1}$

- $\mathrm{l}_{\mathrm{i}} \in \mathfrak{R}$ : Distal distance defined as the distance from the center of gravity to the connect joint of the next link $\mathrm{C}_{\mathrm{i}+1}$

The kinematic and dynamic models will be elaborated in the three dimensional space, as a result the three dimensional parameters are:

- $\mathrm{M}_{\mathrm{i}} \in \mathfrak{R}^{3 \times 3}$ : mass matrix of the link $\mathrm{C}_{\mathrm{i}}$ given by:

$$
\mathrm{M}_{\mathrm{i}}=\left(\begin{array}{ccc}
\mathrm{m}_{\mathrm{i}} & 0 & 0 \\
0 & \mathrm{~m}_{\mathrm{i}} & 0 \\
0 & 0 & \mathrm{~m}_{\mathrm{i}}
\end{array}\right)
$$

Table 3: Physical parameters

\begin{tabular}{lcccccc}
\hline & & \multicolumn{3}{l}{$\begin{array}{l}\text { Link } \\
\text { distance }(\mathrm{m})\end{array}$} & $\begin{array}{l}\text { Mass } \\
(\mathrm{Kg})\end{array}$ & \multicolumn{4}{l}{$\begin{array}{l}\text { Inertia about centre of } \\
\text { mass }\left(\mathrm{Kg} \mathrm{m}^{-2}\right)\end{array}$} & $\begin{array}{l}\text { Proximal } \\
\text { distance } \\
(\mathrm{m})\end{array}$ & Distal \\
\hline Right foot & 1.015 & 0.001 & 0.001 & 0.002 & 0.034 & 0.034 \\
Right leg & 3.255 & 0.051 & 0.051 & 0.004 & 0.184 & 0.241 \\
Right thigh & 7.000 & 0.113 & 0.113 & 0.017 & 0.184 & 0.240 \\
Pelvis & 9.940 & 0.112 & 0.112 & 0.472 & 0.021 & 0.178 \\
Left thigh & 7.000 & 0.113 & 0.113 & 0.017 & 0.240 & 0.184 \\
Left leg & 3.255 & 0.051 & 0.051 & 0.004 & 0.241 & 0.184 \\
Left foot & 1.015 & 0.001 & 0.001 & 0.002 & 0.034 & 0.034 \\
Trunk & 24.850 & 0.332 & 0.332 & 1.458 & 0.206 & 0.093 \\
Head and neck & 5.670 & 0.012 & 0.012 & 0.012 & 0.157 & 0.157 \\
Right arm & 1.960 & 0.018 & 0.018 & 0.002 & 0.140 & 0.181 \\
Right forearm & 1.120 & 0.006 & 0.006 & 0.001 & 0.109 & 0.144 \\
Right hand & 0.420 & 0.001 & 0.001 & 0.000 & 0.095 & 0.092 \\
Left arm & 1.960 & 0.018 & 0.018 & 0.002 & 0.140 & 0.181 \\
Left forearm & 1.120 & 0.006 & 0.006 & 0.001 & 0.109 & 0.144 \\
Left hand & 0.420 & 0.001 & 0.001 & 0.000 & 0.095 & 0.092 \\
\hline
\end{tabular}

- $\mathrm{I}_{\mathrm{i}} \in \mathfrak{R}^{3 \times 3}$ : Inertia matrix about the center of mass of the link Ci described by:

$$
I_{i}=\left(\begin{array}{ccc}
i_{i x} & 0 & 0 \\
0 & i_{\text {iy }} & 0 \\
0 & 0 & i_{i z}
\end{array}\right)
$$

- $\mathrm{K}_{\mathrm{i}} \in \mathfrak{R}^{3 \times 3}$ : Proximal distance vector of the link $\mathrm{C}_{\mathrm{i}}$ given by:

$$
\mathrm{K}_{\mathrm{i}}=\left[\begin{array}{lll}
0 & 0 & \mathrm{k}_{\mathrm{i}}
\end{array}\right]^{\mathrm{T}}
$$

- $\mathrm{L}_{\mathrm{i}} \in \mathfrak{R}^{3 \times 3}$ : Distal distance vector of the link $\mathrm{C}_{\mathrm{i}}$ described by:

$$
\mathrm{L}_{\mathrm{i}}=\left[\begin{array}{lll}
0 & 0 & \mathrm{l}_{\mathrm{i}}
\end{array}\right]^{\mathrm{T}}
$$

To determine all physical parameters corresponding to each link $\mathrm{C}_{\mathrm{i}}$, we use the Winter, (2009) statistical model that provides satisfying results for the determination of the mass $\mathrm{M}_{\mathrm{i}}$, the voluminous density, the length, the proximal distance $\mathrm{K}_{\mathrm{i}}$, distal distance $\mathrm{L}_{\mathrm{i}}$ and the inertia about the center of mass $\mathrm{I}_{\mathrm{i}}$. It consists on associating each rigid body to a geometric form. For example, legs and thighs are assimilated to cylinders whereas trunk and pelvis are represented by parallelepipeds. Obtained results are given in Table 3.

Kinematic modeling: Modeling the proposed humanoid robot implies first to establish the kinematic model and then to set the dynamic model. Kinematic model is basically founded on Euler's transformation matrix (Hemami, 1982). In fact, each link is considered as a rigid body with three rotational degrees of freedom. The angular position $\dot{\xi}=\left[\psi_{\mathrm{i}}, \Phi_{\mathrm{i}}, \theta_{\mathrm{i}}\right]$ of each link is 
measured by Euler angles. Let $\mathrm{ox}_{\mathrm{i} 0}, \mathrm{oy}_{\mathrm{i} 0}$ and $\mathrm{oz}_{\mathrm{i} 0}$ axes form the inertial coordinate system while $\mathrm{ox}_{\mathrm{i} 1}, \mathrm{oy}_{\mathrm{i} 1}$ and $\mathrm{OZ}_{\mathrm{i} 0}$ are axis of body coordinates system. The Euler angles of a rigid body are generated by three successive rotations of the rigid body about the body coordinate system. Suppose that the two coordinate systems coincide initially, the angle $\psi_{\mathrm{i}}$ is formed by rotating the body about $\mathrm{oz}_{\mathrm{i} 1}$. This corresponds to the yaw motion. For the second rotation, $\Phi_{\mathrm{i}}$ is generated by rotating the body about $\mathrm{ox}_{\mathrm{i} 2}$ axe. This rotation represents the rollover action of the body. Finally, the pitch motion of the body is described by angle $\theta_{\mathrm{i}}$ about the axe $\mathrm{oy}_{\mathrm{i} 3}$. A rotation from a coordinate system to another may be represented by a matrix transformation (Hemami, 1982). For an $n$-link robot, let $X=\left[X_{1} \ldots X_{i} \ldots X_{n}\right]^{T}$ be the vector of Cartesian positions for link centers of gravity and let $\mathrm{A}_{\mathrm{i}}$ be the transformation matrix from the body coordinate system to the inertial coordinate system. The robot kinematic model is then given by:

$\mathrm{X}_{\mathrm{i}}=\mathrm{A}_{\mathrm{i}}\left(\mathrm{L}_{\mathrm{i}}-\mathrm{K}_{\mathrm{i}}\right)+\mathrm{X}_{\mathrm{i}-1}, \forall \mathrm{i} \in[1, \ldots, \mathrm{n}]$

For each link $\mathrm{C}_{\mathrm{i}}$, the relationship between angular velocity $\mathrm{W}_{\mathrm{i}}$ and Euler angles velocity $\xi_{\mathrm{i}}$ is:

$\mathrm{W}_{\mathrm{i}}=\mathrm{B}_{\mathrm{i}}\left(\xi_{\mathrm{i}}\right)^{-1} \xi_{\mathrm{i}}$

The inverse matrix of $\mathrm{B}_{\mathrm{i}}^{-1}$ is described by:

$\mathrm{B}_{i}=\left(\begin{array}{ccc}\frac{-\sin \theta_{i}}{\cos \Phi_{i}} & 0 & \frac{\cos \theta_{i}}{\cos \Phi_{i}} \\ \cos \theta_{i} & 0 & \sin \theta_{i} \\ \frac{\sin \theta_{i} \sin \Phi_{i}}{\cos \Phi_{i}} & 1 & \frac{-\cos \theta_{i} \sin \Phi_{i}}{C \Phi_{i}}\end{array}\right)$

Angular acceleration can be then written as follows:

$\left.\dot{\mathrm{W}}_{\mathrm{i}}=\frac{\mathrm{d}}{\mathrm{dt}}\left(\mathrm{B}_{\mathrm{i}}^{-1} \dot{\xi}_{\mathrm{i}}\right)=+\dot{\mathrm{B}}_{\mathrm{i}}^{-1} \dot{\xi}_{\mathrm{i}}+\mathrm{B}_{\mathrm{i}}^{-1} \xi_{\mathrm{i}}\right)$

Dynamic modeling: The dynamic model is computed using the Newton-Euler method that is more efficient with respect to the calculation cost than the Lagrange approach for a robot with a large number of joints. In order to reach the dynamic model of both upper and lower bodies of the proposed humanoid prototype, we use Hemami (2002) and Hemami and Utkin (2002) works and we suggest a generalized motion equation for the rotation as in (5) and the translation as in (6) of each link $\mathrm{C}_{\mathrm{i}}$ :

$\mathrm{I}_{\mathrm{i}} \dot{\omega}_{1}=\mathrm{f}_{\mathrm{i}}+\mathrm{F}_{\mathrm{i}}+\mathrm{F}_{\mathrm{i}+1}+\mathrm{G}_{\mathrm{i}}+\mathrm{G}_{\mathrm{i}+1}+\tau_{\mathrm{i}}+\tau_{\mathrm{i}+1}$
$\mathrm{M}_{\mathrm{i}} \ddot{\mathrm{X}}_{1}=\mathrm{M}_{\mathrm{i}} \mathrm{g}+\Gamma_{\mathrm{i}}+\Gamma_{\mathrm{i}+1}$

Where:

$\mathrm{I}_{\mathrm{i}}=$ Inertia of the link $\mathrm{C}_{\mathrm{i}}$

$\dot{\omega}_{\mathrm{i}}=$ Angular acceleration of the link $\mathrm{C}_{\mathrm{i}}$

$\mathrm{F}_{\mathrm{i}}=$ Torque due to the holonom force applied to the proximal articulation of the link $\mathrm{C}_{\mathrm{i}}$ expressed in the body coordinate system

$\mathrm{F}_{\mathrm{i}+1}=$ Torque due to the holonom force applied to the distal articulation of the link $\mathrm{C}_{\mathrm{i}}$ expressed in the body coordinate system

$\mathrm{G}_{\mathrm{i}}=$ Non-holonom torque applied to the proximal articulation of the link $\mathrm{C}_{\mathrm{i}}$ expressed in the body coordinate system

$\mathrm{G}_{\mathrm{i}+1}=$ Non-holonom torque applied to the distal articulation of the link $\mathrm{C}_{\mathrm{i}}$ expressed in the body coordinate system

$\tau_{\mathrm{i}}=$ Muscular torque applied to the proximal articulation of the link $\mathrm{C}_{\mathrm{i}}$ expressed in the body coordinate system

$\tau_{i+1}=$ Muscular torque applied to the distal articulation of the link $\mathrm{C}_{\mathrm{i}}$ expressed in the body coordinate system

$\mathrm{M}_{\mathrm{i}}=$ Mass of the link $\mathrm{C}_{\mathrm{i}}$

$\ddot{X}_{\mathrm{i}}=$ Linear acceleration of the link $\mathrm{C}_{\mathrm{i}}$

$\Gamma_{\mathrm{i}}=$ Holonom force applied to the proximal articulation of the link $\mathrm{C}_{\mathrm{i}}$ expressed in the inertial coordinate system

$\Gamma_{\mathrm{i}+1}=$ Holonom force applied to the distal articulation of the link $\mathrm{C}_{\mathrm{i}}$ expressed in the inertial coordinate system

$\mathrm{f}_{\mathrm{i}}=$ Intrinsic torque of the link $\mathrm{C}_{\mathrm{i}}$ expressed in the body coordinates system $\left(\mathrm{x}_{\mathrm{i}}, \mathrm{y}_{\mathrm{i}}, \mathrm{z}_{\mathrm{i}}\right)$ and relating angular velocity to the link inertia. It is described by:

$\mathrm{f}_{\mathrm{i}}=\mathrm{f}\left(\mathrm{W}_{\mathrm{i}}\right)=\mathrm{I}_{\mathrm{i}} \mathrm{W}_{\mathrm{i}} \times \mathrm{W}_{\mathrm{i}}$

Human body's balance of forces and torques reveals that humanoid limbs are subject to three kinds of forces (Hemami and Utkin, 2002): Holonom, non holonom and muscular forces. Holonom forces and torques result of the interaction between a limb and the limbs to which it is related. These forces and torques given in (8) and (9) are ensuring the cohesion of human body limbs:

$\mathrm{F}_{\mathrm{i}}= \pm \mathrm{K}_{\mathrm{i}} \mathrm{A}_{\mathrm{i}}^{\mathrm{T}} \Gamma_{\mathrm{i}}$

$\mathrm{F}_{\mathrm{i}+1}= \pm \mathrm{L}_{\mathrm{i}} \times \mathrm{A}_{\mathrm{i}}^{\mathrm{T}} \Gamma_{\mathrm{i}+1}$ 


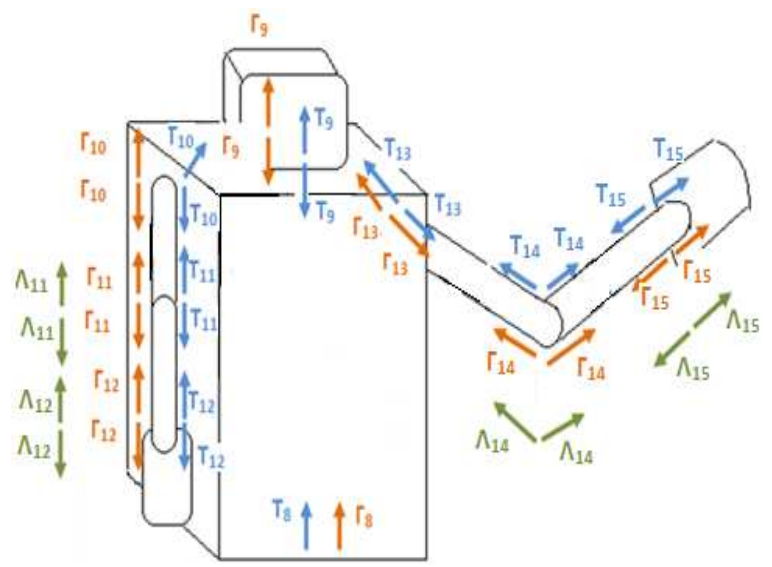

Fig. 2: Applied forces and torques to the humanoid upper body

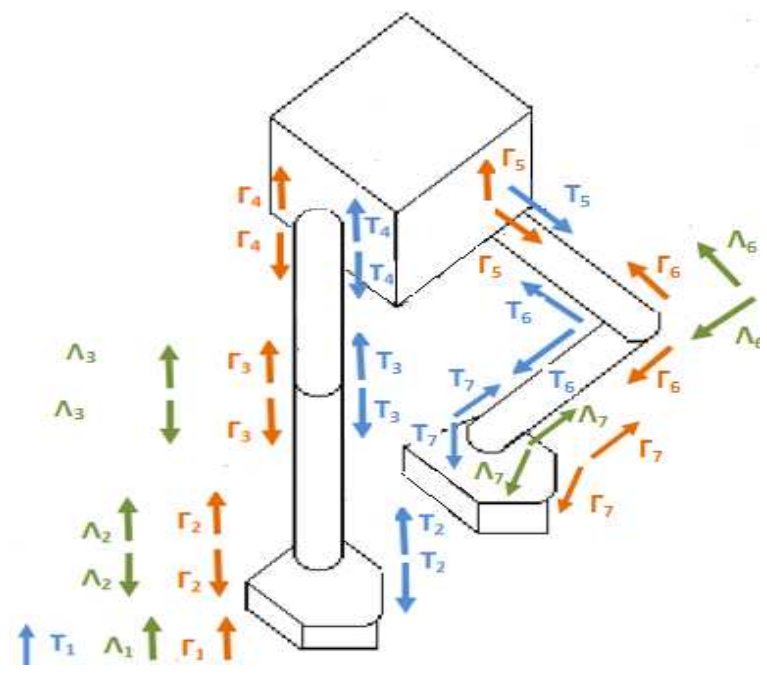

Fig. 3: Applied forces and torques to the humanoid lower body

A limb is also subject to an effort in order to remain aligned with the previous limb. This effort is resulting from non-holonom torques given in (10) and (11) which can be found in articulations with a number of degrees of freedom lower than three:

$$
\begin{gathered}
\mathrm{G}_{\mathrm{i}}= \pm \mathrm{A}_{\mathrm{i}}^{\prime} \mathrm{A}_{\mathrm{i}-1} \mathrm{R}_{\mathrm{i}} \Lambda_{\mathrm{i}} \\
\mathrm{G}_{\mathrm{i}+1}= \pm \mathrm{R}_{\mathrm{i}+1} \Lambda_{\mathrm{i}+1}
\end{gathered}
$$

Where:

$\Lambda_{\mathrm{i}}=$ Non-holonom torque applied to the proximal articulation of the link $\mathrm{C}_{\mathrm{i}}$ expressed in the body coordinate system of the previous link $\mathrm{C}_{\mathrm{i}-1}$
$\Lambda_{\mathrm{i}+1}=$ Non holonom torque applied to the distal articulation of the link $C_{i}$ expressed in the body coordinate system

$\mathrm{R}_{\mathrm{i}}$ and $\mathrm{R}_{\mathrm{i}+1}=$ Matrix of mechanical relations between the humanoid rigid bodies that are subject to non-holonom forces

Finally, mechanic torques are muscular torques applied by human body's muscles to move limbs. They are described by:

$$
\begin{aligned}
\tau_{\mathrm{i}} & = \pm \mathrm{A}_{\mathrm{i}} \mathrm{A}_{\mathrm{i}-1} \mathrm{~T}_{\mathrm{i}} \\
\tau_{\mathrm{i}+1} & = \pm \mathrm{T}_{\mathrm{i}+1}
\end{aligned}
$$

Where:

$\mathrm{T}_{\mathrm{i}}=$ Muscular torque applied to the proximal articulation of the link $\mathrm{C}_{\mathrm{i}}$ expressed in the body coordinate system of the previous link $\mathrm{C}_{\mathrm{i}-1}$

$\mathrm{T}_{\mathrm{i}+1}=$ Muscular torque applied to the distal articulation of the link $\mathrm{C}_{\mathrm{i}}$ expressed in the body coordinate system

Figure 2 and 3 shows the applied forces and torques to the humanoid lower body and the humanoid upper body respectively.

\section{RESULTS}

Lower body: The lower limbs are the key structure for biped locomotion as the humanoid lower body ensures the generation of a walking step. In fact, a typical walking cycle may include three phases (Cho et al., 2009; Hemami and Zheng, 1984; Katic et al., 2008; Chen et al., 1986): The Single Support Phase (SSP) occurs when one limb is pivoted to the ground while the other is swinging from the rear to the front. At the beginning of this stage, the heel of the forward foot is lifted with the toe used as a pivot. When a sufficient rotational motion is done, the foot is to be completely off the ground and swings in the air. A free dynamic model corresponds to the single support phase. The second phase is the Impact Phase (IP) and it occurs when the toe of the forward foot starts touching the ground, the impact between the toe of the swing leg and the ground takes place during an infinitesimal length of time. The Double Support Phase (DSP) is the last stage of the walking cycle, when both limbs remain in contact with the ground. This phase begins with the heel of the forward foot touching the ground then foot rotational motion continues until the entire sole of the foot becomes in contact with the ground and it ends with the 
toe of the rear foot taking off the ground. The length of this phase depends on the walking cycle's rhythm. During all these phases, the other foot, that is the supporting foot, does not change its position and orientation and the whole part of its sole is in contact with the ground. As soon as the third phase of the swing foot ends, the foot of the supporting leg goes into its own first stage of the swing motion.

For both impact phase and double support phase, we may associate a constraint dynamic model. Indeed, we get the dynamic model of the humanoid robot lower body by using the Newton-Euler methodology. Holonom forces and muscular torques are applied to every articulation whereas non-holonom forces are only to be found in the articulations of ankles $J_{1}$ and $J_{7}$ and knees $\mathbf{J}_{2}$ and $\mathbf{J}_{6}$. The upper body dynamic model can be written as:

$\mathrm{P}_{1} \mathrm{Z}_{1}=\mathrm{P}_{2}+\mathrm{P}_{2} \Gamma+\mathrm{P}_{4} \Lambda+\mathrm{P}_{5} \mathrm{~T}$

Where:

$\mathrm{Z}_{1} \quad=$ The state vector of the system composed of angular and linear accelerations

$\Gamma, \Lambda$ and $\mathrm{T}=$ The holonom, non-holonom and muscular forces and torques respectively

Matrices $\mathrm{P}_{1}-\mathrm{P}_{5}$ of appropriate dimensions include on the one hand the different products between proximal/distal distances and Euler's transformation matrices and on the other hand inertias and masses of the rigid body whose forces and torques are at play.

Upper body: The upper body modeling doesn't require establishing both free and constraint models. Actually, it only calls for free robotic dynamic model because the function attributed to this part of the humanoid robot consists on swinging his arms or holding up his hand in a sign of greeting. It doesn't include grasping objects or opening doors. Holonom forces and muscular torques are applied to every articulation whereas non-holonom forces are only to be found in the articulations of elbows $\mathrm{J}_{10}$ and $\mathrm{J}_{13}$ and wrists $\mathrm{J}_{11}$ and $\mathrm{J}_{14}$. The upper body robotic system can be written as follows:

$\mathrm{P}_{6} \mathrm{Z}_{2}=\mathrm{P}_{7}+\mathrm{P}_{8} \Gamma+\mathrm{P}_{9} \Lambda+\mathrm{P}_{10} \mathrm{~T}$

Matrices $\mathrm{P}_{6-10}$ of appropriate dimensions include on the one hand the different products between proximal/distal distances and Euler's transformation matrices and on the other hand inertias and masses of the rigid body whose forces and torques are at play.
Lower and upper bodies free robotic models and Control laws synthesis: Finally, we can get for the lower and upper bodies the general robotic dynamic model described by:

$\mathrm{J}(\Phi) \ddot{\Phi}+\mathrm{H}(\Phi, \dot{\Phi})+\mathrm{G}(\Phi)=\mathrm{D} \cdot \tau$

Where:

$\Phi=\quad=$ The state vector describing the humanoid robot system

$\mathrm{J}(\Phi) \quad=$ The positive definite inertia matrix

$\mathrm{H}(\Phi, \dot{\Phi})=$ The vector of the Coriolis and centripetal torques

$\mathrm{G}(\Phi)=$ The positive definite gravity vector

$\mathrm{D}=\mathrm{A}$ nonsingular input map matrix

$\tau \quad=$ The vector of control inputs

To ensure the foot motion during the single support phase and the arm swing, a PD control law is used. We impose to the free robotic systems the following second order linear input-output behavior (Hemami and Zheng, 1984; Tzafestas et al., 1993):

$\ddot{\Phi}+\mathrm{K}_{\mathrm{V}} \dot{\Phi}+\mathrm{K}_{\mathrm{P}}\left(\Phi-\Phi_{\mathrm{d}}\right)=0$

$\mathrm{K}_{\mathrm{V}} \in \Re^{\mathrm{n}^{* \mathrm{n}}}$ and $\mathrm{K}_{\mathrm{P}} \in \mathfrak{R}^{\mathrm{n}^{* \mathrm{n}}}$ are two diagonal matrices chosen positive definite to guarantee global stability, desired performances and decoupling proprieties for the controlled system. To obtain a critically damped closed-loop performance, If $\lambda$ is the desired bandwidth, we must select (Tzafestas et al., 1993):

$\mathrm{K}_{\mathrm{v}}=\operatorname{diag}[2 \lambda]$ and $\mathrm{K}_{\mathrm{P}}=\operatorname{diag}\left[\lambda^{2}\right]$

The control law obtained from relations (16) and (17) is described by:

$\tau=\mathrm{D}^{-1}\left(\mathrm{~J}(\Phi)\left[-\mathrm{K}_{\mathrm{v}} \Phi-\mathrm{K}_{\mathrm{p}}\left(\Phi-\Phi_{\mathrm{d}}\right)\right]+\mathrm{H}\left(\Phi-\Phi_{\mathrm{d}}\right)+\mathrm{G}(\Phi)\right)$

Regarding the lower body, the step walking parameters are closely inspired from Oberg et al. (1993) study on basic gait parameters. In this experimentation, basic temporal gait parameters were collected from 233 healthy subjects (116 men and 117 women, 10-79 years of age) during slow, normal and fast gait. The most frequently used gait parameters are velocity, step length and step frequency. Using Oberg et al. (1993) results and assuming that the female humanoid robot subject of our research is 26 years old and has a normal gait, we easily get the humanoid robot gait parameters shown in Table 4. 
Table 4: Basic gait parameters for a women with a normal gait

\begin{tabular}{llll}
\hline Age (years) & $\begin{array}{l}\text { Gait speed } \\
\left(\mathrm{m} \mathrm{sec}^{-1}\right)\end{array}$ & $\begin{array}{l}\text { Step frequency } \\
\left(\mathrm{steps} \mathrm{sec}^{-1}\right)\end{array}$ & $\begin{array}{l}\text { Step length } \\
(\mathrm{m})\end{array}$ \\
\hline $20-29$ & 1.24 & 2.08 & 0.59 \\
\hline
\end{tabular}

Table 5: bandwidth selection

\begin{tabular}{lllc}
\hline$\lambda$ & $\begin{array}{l}\text { Half step } \\
\text { duration }(\mathrm{sec})\end{array}$ & $\begin{array}{l}\text { Processing } \\
\text { time }(\mathrm{sec})\end{array}$ & $\begin{array}{l}\text { Maximal torque } \\
\left(\mathrm{N} \mathrm{m}^{-1}\right)\end{array}$ \\
\hline 5 & 1.60 & 0.13 & 40 \\
12 & 0.50 & 0.12 & 231 \\
30 & 0.25 & 0.13 & 1395 \\
\hline
\end{tabular}

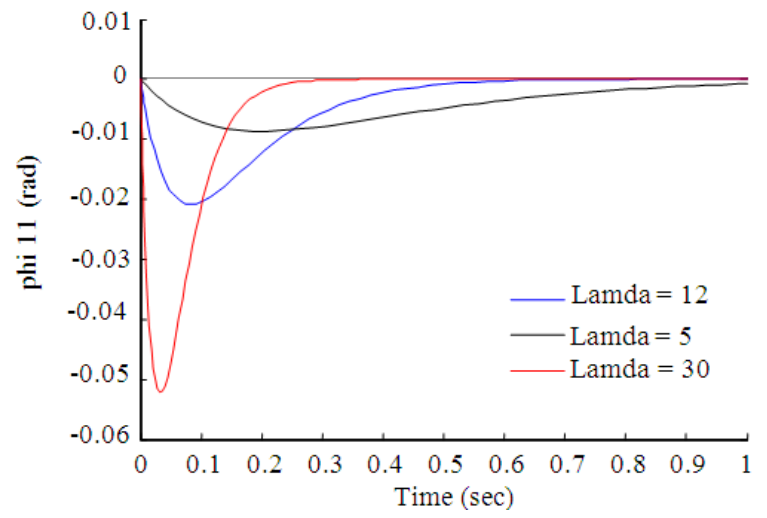

Fig. 4: Angular velocity $\Phi_{11}$ for three different bandwidths

For the simulations of the lower body free robotic system, we are only considering the achievement of a half step. Thus, a half step length should be $0.29 \mathrm{~m}$ and it should stay $0.25 \mathrm{sec}$. The determination of the bandwidth implies first to vary it and compare data for the half step duration, the processing time and the value of the maximal torque in order to choose the suitable bandwidth. Obtained results are given in Table 5 and Fig. 4.

To fulfill the half step duration condition of $0.25 \mathrm{~s}$, the bandwidth of 30 should be chosen but in this case an unrealistic torque would be implied $\left(1395 \mathrm{~N} \mathrm{~m}^{-1}\right)$. To get an attainable torque, we assume that a half step duration of $0.5 \mathrm{~s}$ is satisfying, the corresponding bandwidth is $\lambda=12$.

Before starting the walking cycle, the Cartesian initial conditions of the swing foot are:

$$
\mathrm{X}_{\text {foot,ini }}=\left[\begin{array}{lll}
0 & 0.01 & 0
\end{array}\right]^{\mathrm{T}}
$$

Using the inverse kinematic modeling principle, a computer program that provides the angular position of the whole lower body of the humanoid robot for a given Cartesian position of only the swing foot has been implemented and the initial angular conditions are:

$$
\Phi_{\text {foot,ini }}=\left[\begin{array}{llllllllllllll}
0.6372 & 0 & 0 & 0 & -1.0629 & 0 & 0 & 0.4293 & 0 & 0
\end{array}\right]^{\mathrm{T}}
$$

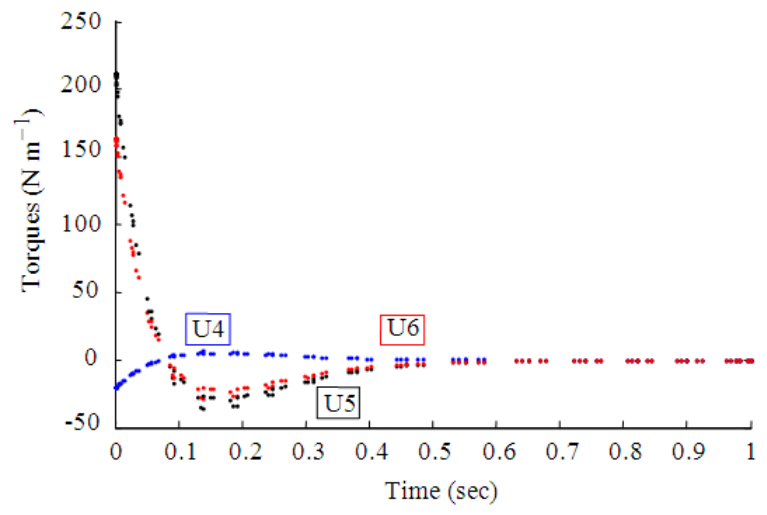

Fig. 5: Stabilization of the right thigh torques

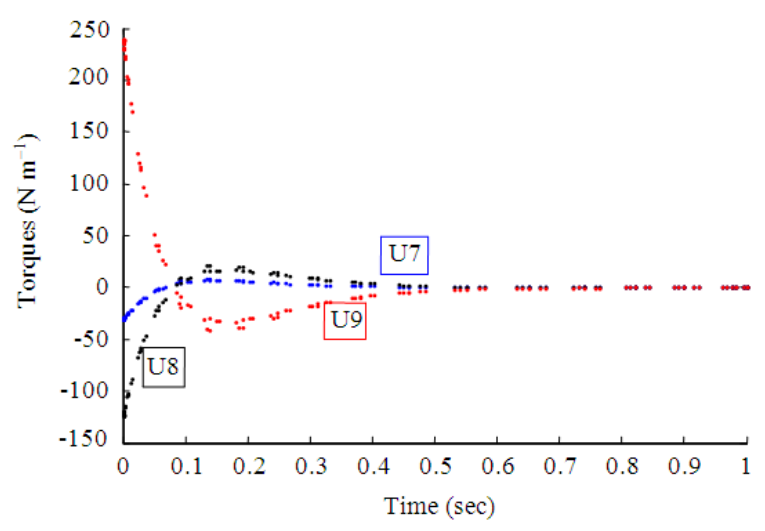

Fig. 6: Stabilization of the left thigh torques

To achieve a half step, the desired Cartesian positions of the swing foot should be:

$$
\mathrm{X}_{\text {foot,des }}=\left[\begin{array}{lll}
0.2955 & 0.01 & 0.1
\end{array}\right]^{\mathrm{T}}
$$

The corresponding desired angular positions are:

$\Phi_{\text {foot,des }}=\left[\begin{array}{lll}0.6325 & 0.1331 & 0.1150-0.0488-1.0604\end{array}\right.$ $0.553-0.10950 .4441-0.1205-0.1404]^{\mathrm{T}}$

After running simulations, Cartesian and angular positions reach desired values. We present below the simulation results for the two hip joints in order to compare each right articulation with its correspondent left one. The right thigh is associated to the swing foot whereas the left thigh is linked to the supporting foot. Figure 5 and 6 represents the torques applied to the three joints of the right thigh and left thigh respectively. For torques related to first and third thigh joints, the same shape curve is observed with the same maximal value reached. We can then conclude that the second right hip joint is responsible for the thigh motion during the single support phase. 


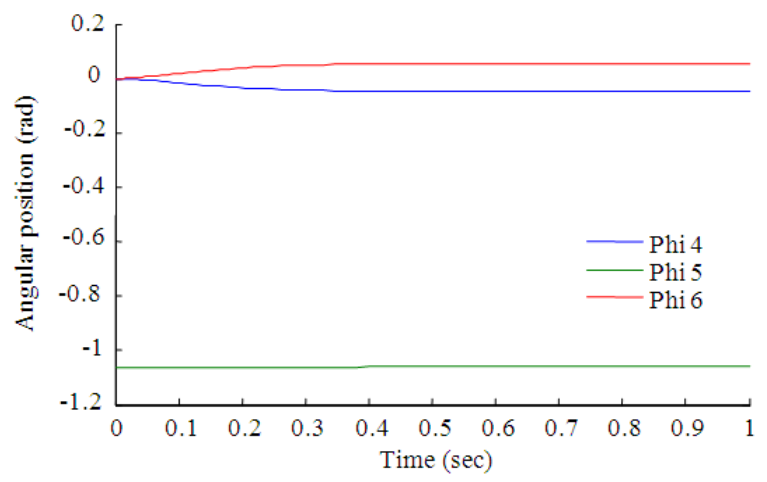

Fig. 7: Stabilization of the right thigh angular positions

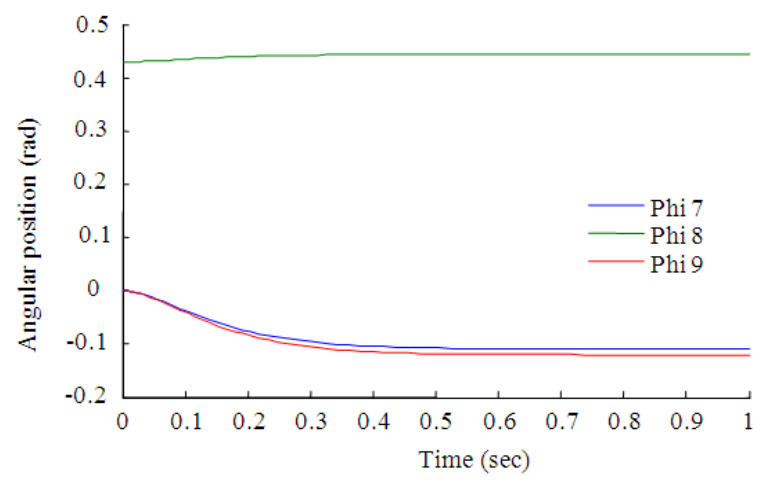

Fig. 8: Stabilization of the left thigh angular positions

Figure 7 and 8 represents the angular positions of the three joints of the right thigh $\xi_{3}=\left[\Phi_{4} \Phi_{5} \Phi_{6}\right]$ and left thigh $\xi_{5}=\left[\Phi_{7} \Phi_{8} \Phi_{9}\right]$ respectively. Finally, Fig. 9 and 10 represents the angular velocities of the three joints of the right thigh and left thigh respectively.

For each of the seven links of the humanoid robot lower body, simulations of torques have emphasized very high values at the beginning of the motion followed by a rapid convergence to zero. Indeed, when the single support phase starts, the deviation between initial and desired values is significant and thus requires a high control values to lead the biped follow the expected motion. Desired angular position values are obtained after $0.5 \mathrm{sec}$.

Regarding the upper body, before starting the arms motion, the Cartesian initial conditions of the two hands are:

$$
\begin{aligned}
\mathrm{X}_{\text {left hand,ini }} & =\left[\begin{array}{lll}
0 & 0 & -0.44
\end{array}\right]^{\mathrm{T}} \\
\mathrm{X}_{\text {right hand,ini }} & =\left[\begin{array}{lll}
0 & 0 & -0.44
\end{array}\right]^{\mathrm{T}}
\end{aligned}
$$

In this posture, the humanoid robot upper body has the arms and hands stretched. As each link is assumed to

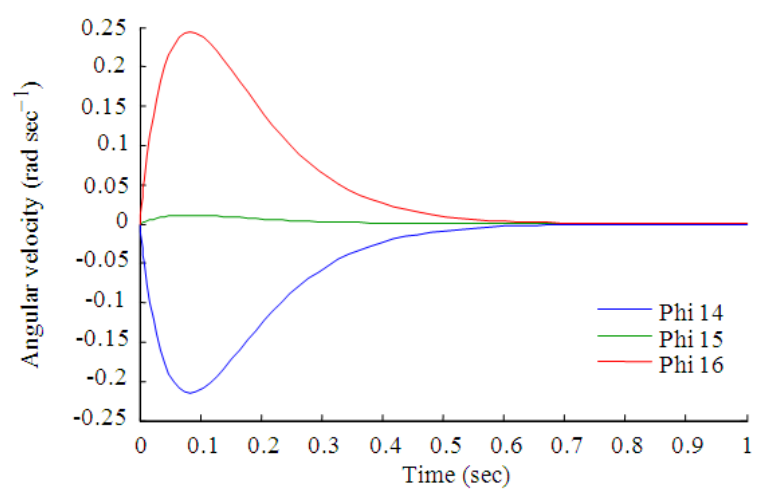

Fig. 9: Stabilization of the right thigh angular velocities

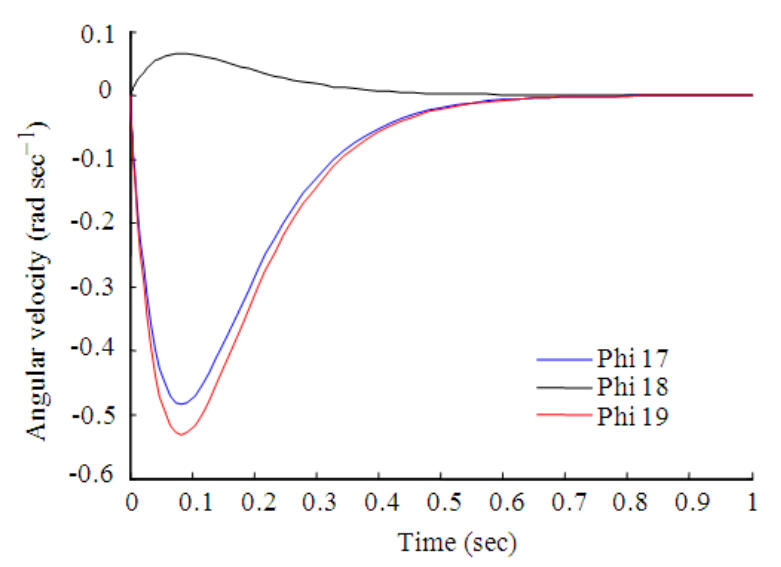

Fig. 10: Stabilization of the left thigh angular velocities

only have a length in the $\mathrm{z}$ axis, there are no consideration of the width and the layer and we can impose the same Cartesian coordinate in the $\mathrm{x}$ and $\mathrm{y}$ axis. To achieve the arms swing, the desired Cartesian positions of the two hands should be:

$$
\begin{aligned}
\mathrm{X}_{\text {left hand,des }} & =\left[\begin{array}{lll}
-0.12 & 0 & -0.4
\end{array}\right]^{\mathrm{T}} \\
\mathrm{X}_{\text {right hand,des }} & =\left[\begin{array}{lll}
0.12 & 0 & -0.44
\end{array}\right]^{\mathrm{T}}
\end{aligned}
$$

This finale posture implies for the right hand a motion from the rear to the front in the $\mathrm{x}$ axis moving from $0-0.12 \mathrm{~m}$ and the opposite motion for the left hand swinging from the front to the rear and thus moving from 0 to $-0.12 \mathrm{~m}$. The swing motion takes $0.5 \mathrm{sec}$.

Figure 11 shows the arms swing during a half step walking in the sagittal plane, transitional postures are given to emphasize the direction followed by each hand. The right hand is supporting the swinging foot in its motion from the rear to the front while the left hand is accompanying the supporting foot in its motion from the front to the rear. 


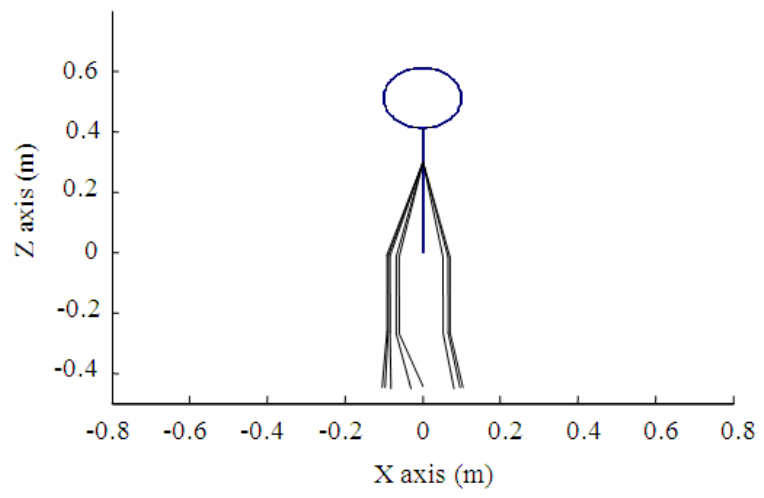

Fig. 11: Arms swing during a step walking

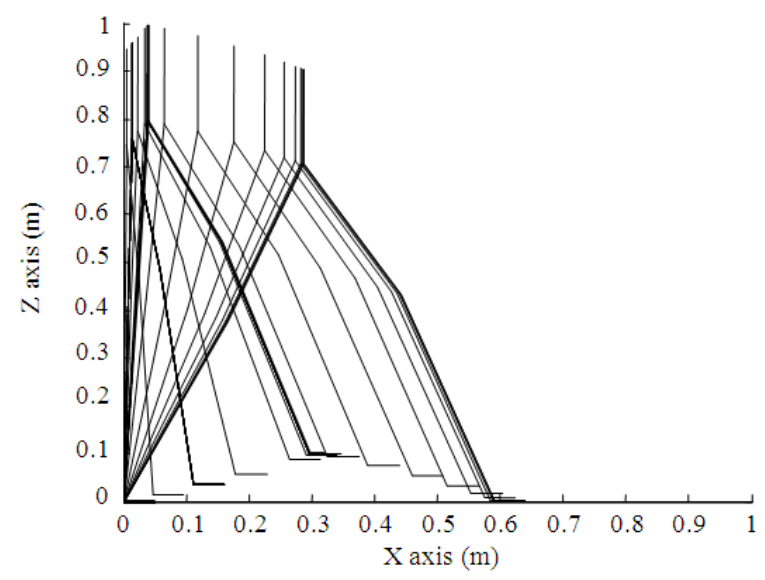

Fig. 12: Stabilization at a step walking

Lower body constraint robotic model and control law synthesis during impact and double support phase: The general robotic constraint dynamic model of the lower body is described by:

$\mathrm{J}(\Phi) \ddot{\Phi}+\mathrm{H}(\Phi, \dot{\Phi})+\mathrm{G}(\Phi)=\mathrm{D} \cdot \tau+\frac{\partial \mathrm{E}}{\partial \Phi} \Gamma_{\mathrm{c}}$

Where:

$\mathrm{E}=$ The contact point

$\Gamma_{\mathrm{c}}=$ The contact force with the ground

During the ground contact, the free end of the biped, at the completion of the step, comes into contact with the ground. This phase is assumed to take place in an infinitesimal time interval. The impact force is described by (Zheng and Hemami, 1985):

$\Gamma_{\text {cimp }}=-\frac{\partial \mathrm{E}}{\partial \Phi} \mid \Phi_{\text {imp }} \mathrm{J}\left(\Phi_{\text {imp }}\right) \Phi\left(\mathrm{t}_{0}^{-}\right)$
Whereas during the double support phase the reaction force is described by (Chen et al., 1986):

$$
\Gamma_{\text {ccont }}=\left[\begin{array}{l}
\left(\frac{\partial \mathrm{E}}{\partial \Phi} \mathrm{J}^{-1}(\Phi) \frac{\partial \mathrm{E}^{\mathrm{T}}}{\partial \Phi}\right)\left(\frac{\partial \mathrm{E}}{\partial \Phi} \mathrm{J}^{-1}(\Phi)\right) \\
{[\mathrm{H}(\Phi, \dot{\Phi})+\mathrm{G}(\Phi)-\mathrm{D} \tau]-\frac{\partial}{\partial \Phi}\left(\frac{\partial \mathrm{E}}{\partial \Phi} \dot{\Phi}\right) \dot{\Phi}}
\end{array}\right]^{-1}
$$

In the above equation, the control torques and the ground reaction force are dependent on each other. Various solutions may be used to find out the ground reaction force expression (Katic et al., 2008; Mehdi and Boubaker, 2010). During the double support phase, the control law obtained from relations (17) and (20) is always described by:

$$
\begin{aligned}
\tau= & \mathrm{D}^{-1}\left(\mathrm{~J}(\Phi)\left[-\mathrm{K}_{\mathrm{v}} \dot{\Phi}-\mathrm{K}_{\mathrm{p}}\left(\Phi-\Phi_{\mathrm{d}}\right)\right]\right. \\
& \left.+\mathrm{H}(\Phi, \Phi)+\mathrm{G}(\Phi)-\frac{\partial \mathrm{E}^{\mathrm{T}}}{\partial \Phi} \Gamma\right)
\end{aligned}
$$

Figure 12 shows the accomplishment of a step of walking in the sagittal plane, transitional postures are given to emphasize the various stages of the right leg during a step. Simulation results of torques, angular positions and velocities for each link of the humanoid robot lower body show stabilization after one second.

\section{CONCLUSION}

A new morphology corresponding to a female humanoid robot and the associated anthropometric model have been introduced. Both three dimensional kinematic and dynamic models of the humanoid robot have been established. The proposed control laws have ensured to the robotic system desired dynamics inspired from experimental gait parameters. Locomotion of the female robot during a whole step walking including the single support, impact and double support phases has been successfully achieved by arm swinging.

\section{REFERENCES}

Aloulou, G.A. and O. Boubaker, 2010. Modeling and controlling a humanoid robot in the three dimensional space. Proceeding of the IEEE International Symposium on Robotics and Intelligent Sensors, Mar. 8-11, IEEE Robotic and Automation Society, Nagoya University, Japan, pp: 376. 
Brooks, R.A., C. Breazeal, M. Marjanovi'c, B. Scassellati and M.M. Williamson, 1999. Computation for Metaphors, Analogy and Agents. In: The Cog Project: Building a Humanoid Robot, Nehaniv, C. (Ed.). Springer-Verlag Heidelberg, ISBN: 978-3540-65959-4, pp: 52-87.

Bruijn, S.M., O.G. Meijer, J.H. Diee, I. Kingma and C.J.C. Lamoth, 2008. Coordination of leg swing, thorax rotations and pelvis rotations during gait: The organization of total body angular momentum. Gait Posture, 27: 455-462. DOI: 10.1016/j.gaitpost.2007.05.017

Chemori, A. and M. Alamir, 2006. Multi-step limit cycle generation for Rabbit's walking based on a nonlinear low dimensional predictive control scheme. Mechatronics, 16: 259-277. DOI: 10.1016/j.mechatronics.2005.12.001

Chen, B.R., M.J. Hines and H. Hemami, 1986. Dynamic modeling for implementation of a right turn in bipedal walking. J. Biomechan., 19: 195-206. PMID: 3700432.

Chesnutt, J., M. Lzu, G. Cheung, J.Kuffner, J. Hodgins and T. Kanade, 2005. Footstep planning for the Honda ASIMO humanoid. IEEE Trans. Robot. Automat., 1: 629-634. http://www.ri.cmu.edu/pub_files/pub4/chestnutt_jo el_2005_1/chestnutt_joel_2005_1.pdf

Chevallereau, C., D.A. Grizzle and J.W. Ching-Long Shih, 2009. Asymptotically stable walking of a five-Link underactuated 3-D bipedal robot. IEEE Trans. Robot., 25: 37-50. DOI: 10.1.1.137.3794

Cho, B.K., I.W. Park and J.H. Oh, 2009. Running pattern generation of humanoid biped with a fixed point and its realization. Int. J. Humanoid Robot. 6: 631-656. DOI: 10.1142/S0219843609001930

Hemami, H. and V.I. Utkin, 2002. On the dynamics and lyapunov stability of constrained and embedded rigid bodies. Int. J. Control, 75: 408-420. DOI: 10.1080/00207170110112232

Hemami, H. and Y.F. Zheng, 1984. Dynamics and control of motion on the ground and in the air with application to biped robots. J. Robot. Syst., l: 101-116. DOI: 10.1002/rob.4620010107
Hemami, H., 1982. Some aspects of Euler-Newton equations of motion. Arch. Applied Mech., 52: 167-176. DOI: 10.1007/BF00535310

Hemami, H., 2002. A general framework for rigid body dynamics, stability and control. J. Dyn. Syst., Measure. Control, 124: 241-252. DOI: 10.1115/1.1468227

Katic, D.M., A.D. Rodic and M.K. Vukobratovic, 2008. Hybrid dynamic control algorithm for humanoid robots based on reinforcement learning. J. Intel. Robot., 51: 3-30. DOI: 10.1007/s10846-007-9174-5

Mehdi, H. and O. Boubaker, 2010. Position/force control for constrained robotic systems: A Lyapunov approach. Proceeding of the IEEE International Symposium on Robotics and Intelligent Sensors, Mar. 8-11, IEEE Robotic and Automation Society, Nagoya University, Japan, pp: 376.

Oberg, T., A. Karsznia and K. Oberg, 1993. Basic gait $\mathrm{x}$ for normal subjects, 10-79 years of age. J. Rehabilitat. Res. Dev., 30: 210-223. http://www.rehab.research.va.gov/jour/93/30/2/pdf/ oberg.pdf

Pontzer, H., J.H. Holloway, D.A. Raichlen and D. E. Lieberman, 2009. Control and function of arm swing in human walking and running. J. Exp. Biol., 212: 523-534. DOI: 10.1242/jeb.024927

Tzafestas, S., M. Raibert and C. Tzafestas, 1993. Comparative simulation study of three control techniques applied to a biped robot. Syst., Man Cybernet., 1: 494-502. DOI: 10.1109/ICSMC.1993.384792

Winter, D.A., 2009. Biomechanics and motor control of human movement. 4th Edn., Wiley Publishers, New York, ISBN: 10: 0470398183, pp: 370.

Zheng, Y.F. and H. Hemami, 1985. Mathematical modeling of a robot collision with its environnement. Int. J. Robot. Res., 2: 289-307. DOI: $10.1002 /$ rob.4620020307 